\title{
Death after hematopoietic stem cell transplantation: changes over calendar year time, infections and associated factors
}

\author{
Jan Styczyński ${ }^{1}$ - Gloria Tridello ${ }^{2}$ Linda Koster ${ }^{3} \cdot$ Simona lacobelli $^{4} \cdot$ Anja van Biezen ${ }^{3} \cdot$ Steffie van der Werf ${ }^{3}$. \\ Małgorzata Mikulska ${ }^{5} \cdot$ Lidia Gil ${ }^{6} \cdot$ Catherine Cordonnier ${ }^{7} \cdot$ Per Ljungman $\mathbb{1}^{8} \cdot$ Diana Averbuch $^{9} \cdot$ Simone Cesaro $\mathbb{1}^{2}$. \\ Rafael de la Camara $\mathbb{D}^{10}$. Helen Baldomero ${ }^{11}$ - Peter Bader ${ }^{12} \cdot{\text { Grzegorz Basak } \mathbb{D}^{13}}^{13}$. Chiara Bonini ${ }^{14}$. \\ Rafael Duarte ${ }^{15} \cdot$ Carlo Dufour $^{16}$ - Jurgen Kuball ${ }^{17}$ - Arjan Lankester ${ }^{18} \cdot$ Silvia Montoto $^{19}$ - Arnon Nagler ${ }^{20}$. \\ John A. Snowden ${ }^{21}$. Nicolaus Kröger ${ }^{22} \cdot$ Mohamad Mohty $^{23} \cdot$ Alois Gratwohl $^{24} \cdot$ for the Infectious \\ Diseases Working Party EBMT
}

Received: 22 July 2018 / Revised: 2 April 2019 / Accepted: 28 May 2019 / Published online: 27 August 2019

(c) The Author(s) 2019. This article is published with open access

\begin{abstract}
Information on incidence, and factors associated with mortality is a prerequisite to improve outcome after hematopoietic stem cell transplantation (HSCT). Therefore, 55'668 deaths in 114'491 patients with HSCT (83.7\% allogeneic) for leukemia were investigated in a landmark analysis for causes of death at day 30 (very early), day 100 (early), at 1 year (intermediate) and at 5 years (late). Mortality from all causes decreased from cohort 1 (1980-2001) to cohort 2 (2002-2015) in all posttransplant phases after autologous HSCT. After allogeneic HSCT, mortality from infections, GVHD, and toxicity decreased up to 1 year, increased at 5 years; deaths from relapse increased in all post-transplant phases. Infections of unknown origin were the main cause of infectious deaths. Lethal bacterial and fungal infections decreased from cohort 1 to cohort 2 , not unknown or mixed infections. Infectious deaths were associated with patient-, disease-, donor type, stem cell source, center, and country- related factors. Their impact varied over the post-transplant phases. Transplant centres have successfully managed to reduce death after HSCT in the early and intermediate post-transplant phases, and have identified risk factors. Late post-transplant care could be improved by focus on groups at risk and better identification of infections of "unknown origin".
\end{abstract}

\section{Introduction}

Besides the risk of relapse, hematopoietic stem cell transplantation (HSCT) remains associated with significant early and late treatment related mortality (TRM). Infections, toxicity, and (after allogeneic HSCT only), graft-vs.-host disease (GVHD) are the main causes of death. An earlier EBMT (European Society for Blood and Marrow Transplantation) analysis of patients with good risk leukemia transplanted between 1980-2001 had shown a significant increase in the 5-year survival rate from the 1980ies to the

Supplementary information The online version of this article (https:// doi.org/10.1038/s41409-019-0624-z) contains supplementary material, which is available to authorized users.

Jan Styczyński

jstyczynski@cm.umk.pl

Extended author information available on the last page of the article. 1990ies, primarily due to a marked reduction of infectious deaths [1]. Since then, HSCT has become established as a valuable treatment option. The number of transplants has substantially increased [2-4], indications for HSCT have broadened [5], and new technologies have been introduced [4, 6-8]. It is estimated today that more than 1.4 million transplants have been performed so far worldwide; about $70^{\prime} 000$ patients are now being treated annually with HSCT, half of them in Europe [3].

The improvement in outcome in the 1990ies has been confirmed by a single centre study for the years 1993-2007 in the United States. It showed a reduction of deaths from organ damage, infections, and severe acute GVHD [2]. No in depth large analysis has been conducted since. New antibiotics, new antifungal and antiviral agents have been introduced [9-14]. The large expansion of unrelated donor registries and the use of haploidentical transplants have given access to donors for many more patients [4]. The introduction of reduced-intensity conditioning transplants 
made HSCT accessible for elderly and frail patients [6]. Still, it remains unknown whether deaths from infections continued to decline since 2001. Furthermore, factors associated with death from infections, a prerequisite for further improvement, are largely unknown. We therefore designed the study to analyse the causes of deaths after HSCT over calendar year time, at specified post-transplant time phases, and searched for factors associated with it. We hypothesized that the key factors differ depending on the time phase after HSCT, both after allogeneic and autologous HSCT.

\section{Patients and methods}

\section{Study design}

This retrospective, observational study included all patients with HSCT from all donor types and stem cell sources for acute lymphoblastic leukemia (ALL), acute myeloid leukemia (AML) or chronic myeloid leukemia (CML) between 1980 and 2015, reported by 588 centers from 51 countries to the EBMT database. This patient selection and the two time periods (cohort 1 from 1980-2001 and cohort 2 from 2002-2015) were based on a previous study, but did include now all disease stages, not only first CR patients [1]. There were no exclusion criteria. All data collection was performed by the IDWP Data Office (Leiden) according to EBMT guidelines (http://www.ebmt.org/retrospectivestudies).

The analysis followed a stepwise approach. First, the data cohort was set up: all transplants in the EBMT data file from 1980 to 2015 were retrieved and assessed for completeness as specified below. In the second step, this file with complete information was closed as of January $1^{\text {st }}$ 2017, and recoded for the specific new grouping of donor type and centre and country specific economic parameters. Data were verified, and the descriptive analysis was performed.

All EBMT teams are required to obtain patients' consent for data transfer to EBMT and to have internal review board approval for their transplant programs. The data set was locked and anonymized. No centers were contacted for missing information. No additional ethics approval was mandated.

\section{Study population}

The study comprised a total number of $114^{\prime} 491$ patients with HSCT, 95'789 (84\%) allogeneic and 18'702 (16\%) autologous, for AML (57.2\%), ALL (25.4\%), or CML (17.4\%); of these $42^{\prime} 997$ (37.6\%) were in cohort 1 , and $71^{\prime}$ $494(62.4 \%)$ in cohort 2 . There were $56.5 \%$ male, $43.5 \%$ female patients with a median age of 37 years $(0-84$ years range) (Table 1).

\section{Working definitions}

Death after transplant was categorized as previously defined $[1,15]$ into death from relapse (RM, relapse mortality: any death after relapse) and death from causes other than relapse (GVHD, toxicity, infection, other and unknown causes). Infectious deaths were analysed as total, and split by bacterial, fungal, viral, parasitic, mixed, and unknown infections.

Disease stage was defined as early disease (CR1 in ALL and AML; first CP in CML) or late disease (all other: $\geq C R 2$, progression, refractory/relapsed).

Donor type was analysed in 10 types as previously described: autologous, syngeneic, HLA-identical sibling donor $\mathrm{HY}^{-}$, HLA-identical sibling donor $\mathrm{HY}^{+}$, matched family donor $\mathrm{HY}^{-}$, matched family donor $\mathrm{HY}^{+}$, matched unrelated donor $\mathrm{HY}^{-}$, matched unrelated donor $\mathrm{HY}^{+}$, mismatched unrelated donor, mismatched family donor $\left(\mathrm{HY}^{+}\right.$ refers to a female donor for a male recipient; $\mathrm{HY}^{-}$to all other donor-recipient sex combinations) [16]. Matching was used as classified by the reporting team, at the time of first report.

Acute GVHD was graded according to previously published criteria [17]. Chronic GVHD was graded as limited or extensive.

Centre specific microeconomic and country specific macroeconomic factors were integrated as previously described [18]. Centre size was defined for each transplant by the number of transplants performed in the centre for the main disease of the patient in the year of the transplant $(0-4$, $5-19,20+$ transplants). Centre experience in years was defined by the number of years that the centre had performed transplants until the year of the transplant of the patient $(0-4,5-19,20+$ years of program). Country macroeconomic status was defined by gross national income (GNI/capita) in 2016: high income, upper middle income, lower middle income (source: www.worldbank.org). Geographical regions were defined as: north-western eastern and southern (see Table 3A and Table 3B for details). JACIE accreditation status (accredited, expired, withdrawn and not accredited) in 2016 was used.

\section{Statistical analysis}

The primary endpoint was to compute the cumulative incidence (CumInc) of overall post-transplant mortality in cohorts 1 and 2. The CumInc of death was reported at specified time phases after the transplant (very early: day +30 , early: day +100 , intermediate: +1 year and late: +5 years) in a landmark approach. Analysis at day +30 
Table 1 Patients population

\begin{tabular}{|c|c|c|c|c|c|c|c|}
\hline & \multicolumn{4}{|c|}{ Year of last transplant } & \multicolumn{2}{|l|}{ Total } & \multirow[t]{4}{*}{$p$ value } \\
\hline & \multicolumn{2}{|c|}{ 1980-2001 } & \multicolumn{2}{|c|}{ 2002-2015 } & & & \\
\hline & $N$ & $\%$ & $N$ & $\%$ & $N$ & $\%$ & \\
\hline & 42997 & 37.55 & 71494 & 62.45 & 114491 & 100.00 & \\
\hline \multicolumn{8}{|l|}{ Sex } \\
\hline Male & 24656 & 57.34 & 40038 & 56.00 & 64694 & 56.51 & $<0.0001$ \\
\hline Female & 18341 & 42.66 & 31456 & 44.00 & 49797 & 43.49 & \\
\hline \multicolumn{8}{|l|}{ Age at last HSCT (years) } \\
\hline Median & 33.1 & & 41.0 & & 37.4 & & $<0.0001$ \\
\hline Range & $0.2-77$. & & $0.0-83$ & & $0.0-83.8$ & & \\
\hline Mean (SD) & 32.24( & & 38.95 & & $36.43(1$ & & \\
\hline $\mathrm{N}$ obs & 42972 & & 71465 & & 114437 & & \\
\hline \multicolumn{8}{|l|}{ Underlying disease } \\
\hline AML & 20132 & 46.82 & 45386 & 63.48 & 65518 & 57.23 & $<0.0001$ \\
\hline ALL & 9431 & 21.93 & 19652 & 27.49 & 29083 & 25.40 & \\
\hline CML & 13434 & 31.24 & 6456 & 9.03 & 19890 & 17.37 & \\
\hline \multicolumn{8}{|l|}{ Stage at last transplant } \\
\hline early & 27495 & 63.95 & 43946 & 61.47 & 71441 & 62.40 & $<0.0001$ \\
\hline late & 15502 & 36.05 & 27548 & 38.53 & 43050 & 37.60 & \\
\hline \multicolumn{8}{|l|}{ Type of HSCT } \\
\hline Allogeneic & 31128 & 72.40 & 64661 & 90.44 & 95789 & 83.67 & $<0.0001$ \\
\hline Autologous & 11869 & 27.60 & 6833 & 9.56 & 18702 & 16.33 & \\
\hline \multicolumn{8}{|l|}{ Stem cell source } \\
\hline BM & 30218 & 70.28 & 15466 & 21.63 & 45684 & 39.90 & $<0.0001$ \\
\hline $\mathrm{PB}$ & 12442 & 28.94 & 53829 & 75.29 & 66271 & 57.88 & \\
\hline $\mathrm{CB}$ & 337 & 0.78 & 2199 & 3.08 & 2536 & 2.22 & \\
\hline \multicolumn{8}{|l|}{ T-cell depletion } \\
\hline no & 14097 & 62.24 & 30792 & 50.67 & 44889 & 53.81 & $<0.0001$ \\
\hline yes in vivo, no ex vivo & 2881 & 12.72 & 26488 & 43.59 & 29369 & 35.21 & \\
\hline yes ex vivo, no in vivo & 3201 & 14.13 & 1357 & 2.23 & 4558 & 5.46 & \\
\hline yes in vivo + ex vivo & 2472 & 10.91 & 2129 & 3.50 & 4601 & 5.52 & \\
\hline \multicolumn{8}{|l|}{ Conditioning regimen } \\
\hline standard & 32708 & 96.38 & 45487 & 70.77 & 78195 & 79.62 & $<0.0001$ \\
\hline reduced & 1230 & 3.62 & 18788 & 29.23 & 20018 & 20.38 & \\
\hline \multicolumn{8}{|l|}{ First HSCT } \\
\hline No & 2906 & 6.76 & 6342 & 8.87 & 9248 & 8.08 & $<0.0001$ \\
\hline Yes & 40091 & 93.24 & 65152 & 91.13 & 105243 & 91.92 & \\
\hline \multicolumn{8}{|l|}{ Geographic regions } \\
\hline north-west & 26319 & 61.21 & 38629 & 54.03 & 64948 & 56.73 & $<0.0001$ \\
\hline south & 14470 & 33.65 & 25987 & 36.35 & 40457 & 35.34 & \\
\hline east & 2208 & 5.14 & 6878 & 9.62 & 9086 & 7.94 & \\
\hline \multicolumn{8}{|l|}{ GNI per capita $2015^{\mathrm{a}}$} \\
\hline High income & 41424 & 96.34 & 63712 & 89.12 & 105136 & 91.83 & $<0.0001$ \\
\hline Upper middle income & 1565 & 3.64 & 7671 & 10.73 & 9236 & 8.07 & \\
\hline Lower middle income & 8 & 0.02 & 111 & 0.16 & 119 & 0.10 & \\
\hline JACIE accreditation 2016 & & & & & & & \\
\hline accredited & 22935 & 53.34 & 36420 & 50.94 & 59355 & 51.84 & $<0.0001$ \\
\hline expired & 7827 & 18.20 & 8439 & 11.80 & 16266 & 14.21 & \\
\hline withdrawn & 279 & 0.65 & 369 & 0.52 & 648 & 0.57 & \\
\hline not accredited & 11956 & 27.81 & 26266 & 36.74 & 38222 & 33.38 & \\
\hline Centre experience $^{b}$ & & & & & & & \\
\hline $0-4$ & 6295 & 14.64 & 2236 & 3.13 & 8531 & 7.45 & $<0.0001$ \\
\hline $5-19$ & 31026 & 72.16 & 29652 & 41.47 & 60678 & 53.00 & \\
\hline $20+$ & 5676 & 13.20 & 39606 & 55.40 & 45282 & 39.55 & \\
\hline Centre size ${ }^{c}$ & & & & & & & \\
\hline $0-4$ & 14940 & 34.75 & 14965 & 20.93 & 29905 & 26.12 & $<0.0001$ \\
\hline $5-19$ & 24345 & 56.62 & 37794 & 52.86 & 62139 & 54.27 & \\
\hline $20+$ & 3712 & 8.63 & 18735 & 26.20 & 22447 & 19.61 & \\
\hline
\end{tabular}

${ }^{\mathrm{a}}$ Atlas methodology

${ }^{b}$ calculated from ProMISE: number of years performing transplants until the year of transplant of the patient

${ }^{c}$ calculated from ProMISE: number of transplants with the same disease and same year of transplant as the patient

All the differences resulted statistically significant $(p<0.0001)$ 
included all patients, the analyses at day +100 , year +1 , year +5 included patients alive at day +30 , day +100 , year +1 , respectively.

Secondary endpoints were, as in the previous report [1], the CumInc of mortality due to relapse, GVHD, infection, other and unknown causes. GVHD was used as "any GVHD ever", not separated by acute or chronic GVHD. The cumulative incidence estimator was applied, with the Gray test being used to compare different groups. Differences in CumInc rates without overlapping of the 95\%CI's were considered as significant.

The cause-specific Cox model was used to detect the factors related to the infection death for the four posttransplant phases. The death due to infection was considered as event of interest and death due to other causes as competing event.

Factors integrated into the analysis were sex and age of the patients, main diagnosis (ALL or AML or CML), stage of the disease, donor/recipient sex matching $\left(\mathrm{HY}^{-}\right.$vs $\left.\mathrm{HY}^{+}\right)$, type of donor (HLA-matched sibling vs other donor types), type of conditioning (RIC vs MAC), source of stem cells ( $\mathrm{PB}$ vs $\mathrm{BM}$ vs $\mathrm{CB}$ ), year and number of transplantation and presence or absence of in vivo and ex vivo T-cell depletion, and macro- and microeconomic center data as explained above. Factors with a $p$-value $<0.2$ from the univariate analysis were included in the multivariate analysis. Factors with a $p$ value of $<0.05$ were considered as significant.

Comparisons for categorical variables were done using the Fisher's exact test or the $\chi^{2}$ test. The proportional hazard assumption was verified using graphical methods: scaled Schoenfeld [19] residuals and graphical checks proposed by Klein-Moeschberger [20] were performed without finding evidence of relevant violations. All the analyses were performed using the statistical software SAS (SAS Institute Inc., Cary, NC, USA) version 9.4.

\section{Results}

\section{Patient population and demographic changes over calendar time}

There were significant differences in absolute numbers, in patients, disease and donor characteristics, as well as in transplant procedure techniques between the two cohorts. Median age increased from 33.1 years to 41.0 years. The proportion and the absolute numbers of patients with AML and ALL increased, the ones of CML decreased. There were more allogeneic HSCT in the second cohort, more transplants with reduced intensity conditioning and more transplants with peripheral blood as stem cell source. Economic factors showed changes, with more transplants in the second cohort from eastern and lower income countries and within non accredited centres; there was an increase in transplants in more experienced centres by patient volume and years of transplants (Table 1).

\section{Main causes of death and changes over post- transplant phase and calendar time}

A total of the $55^{\prime} 668$ patients were reported as having died, $52^{\prime} 448$ thereof during the observation period $(45.8 \%$ of all patients; 43'930 after allogeneic, 8'518 after autologous HSCT): $22^{\prime} 518$ (42.9\%) died from relapse, 8'361 (15.9\%) from GvHD, 11'701 (22.3\%) from infections, 8028 (15.3\%) from other, and 1540 (2.9\%) from unknown causes (Table 2A and Table 2B). There were major differences between allogeneic (Table 2A, S5) and autologous (Table 2B, S6) HSCT, regarding main causes of death, changes over post-transplant phases and changes over calendar year time (Figs. 1-3, Fig. S1A). Main cause of death was relapse after both, allogeneic $(38.7 \%)$ and autologous (64.5\%), followed by infections (23.8\% allogeneic; $14.8 \%$ autologous), and GvHD (19.0\% allogeneic only). After allogeneic HSCT, $15^{\prime} 418(35.1 \%)$ of all deaths occurred during the first 100 days, $10^{\prime} 174$ (23.0\%) between 1 and 5 years after the transplant, in contrast to autologous HSCT with $1587(18.6 \%)$ of deaths within the first 100 days and $2925(34.3 \%)$ of deaths between 1 and 5 year post-transplant.

The changes in mortality from cohort 1 to cohort 2 differed between allogeneic and autologous HSCT for the four post-transplant periods. In the landmark analysis, the cumulative incidence of overall mortality decreased from cohort 1 to cohort 2 at $+30 \mathrm{~d}(p<0.001)$, at $+100 \mathrm{~d}(p<$ $0.001)$, and at $+1 \mathrm{y}(p<0.001)$, but increased at $+5 \mathrm{y}(p<$ 0.01) (Fig. 1, Table 2A and Table 2B, Table S1A). After autologous HSCT, the cumulative incidence for overall mortality decreased in each of the four post-transplant phases for each cause of death, including relapse except for "other" causes of death in very late phase (Table 2A and Table 2B, S1B). After allogeneic HSCT, mortality from GVHD, and other causes decreased in the very early, early, and intermediate phases, but increased in the late phase for GVHD and for other causes (Fig. 2, Table 2A and Table 2B, S1C). Mortality from relapse increased in all post-transplant phases. As a result, overall mortality decreased in the very early $(+\mathrm{d} 30 ; p<0.0001)$ and early phase $(+\mathrm{d} 100 ; p<$ $0.0001)$, but increased in the late phase $(+5 \mathrm{y}: p<0.0001)$ (Table 2A and Table 2B, S1C).

\section{Causes of infectious death and changes over post- transplant phase and calendar year time}

A total of $11^{\prime} 941$ patients died of infectious complications. The majority of lethal infections $(59.4 \%)$ were of unknown etiology, $14.7 \%$ were of bacterial, $10.6 \%$ of fungal, $9.2 \%$ of 

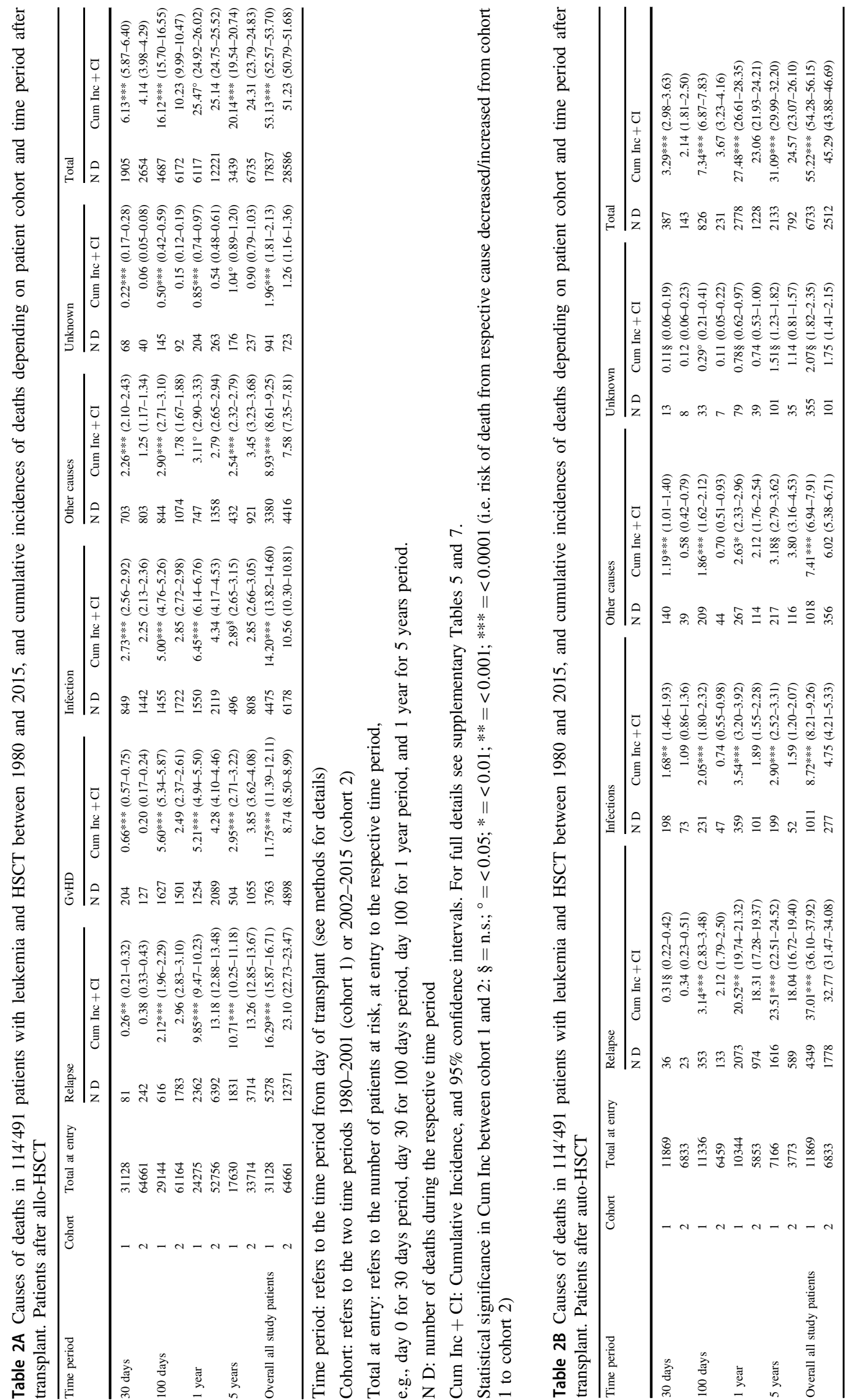

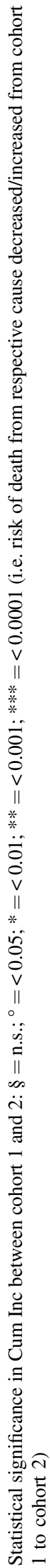



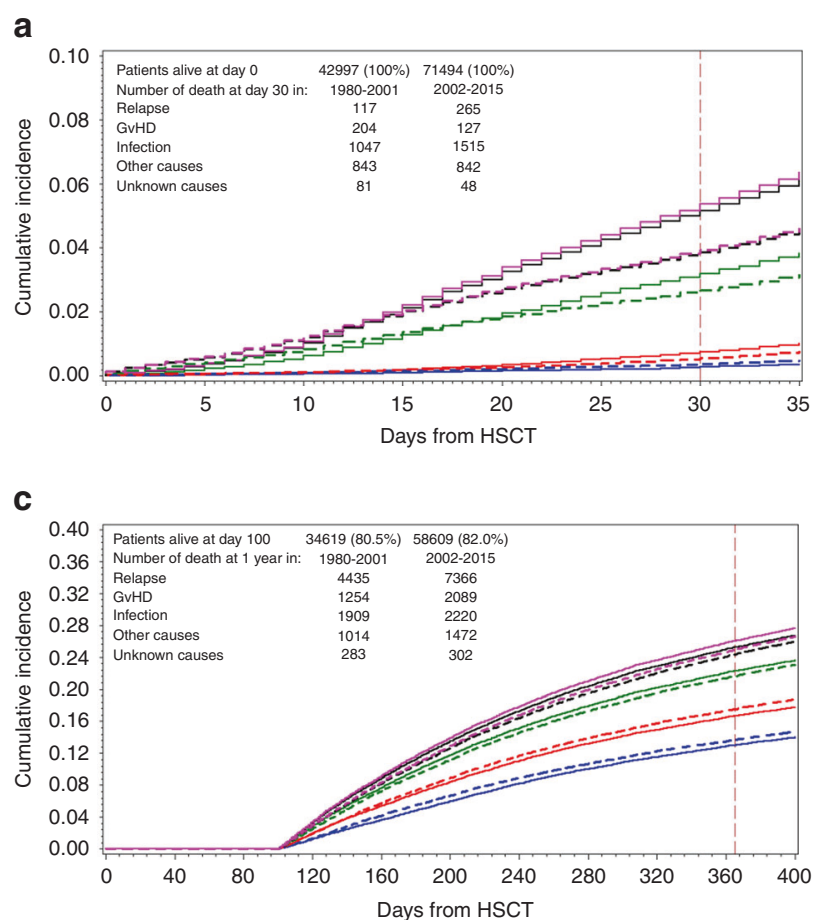
transplant phases and from cohort 1 to cohort 2 . The stacked curves for the four post-transplant phases for the two cohorts combined in

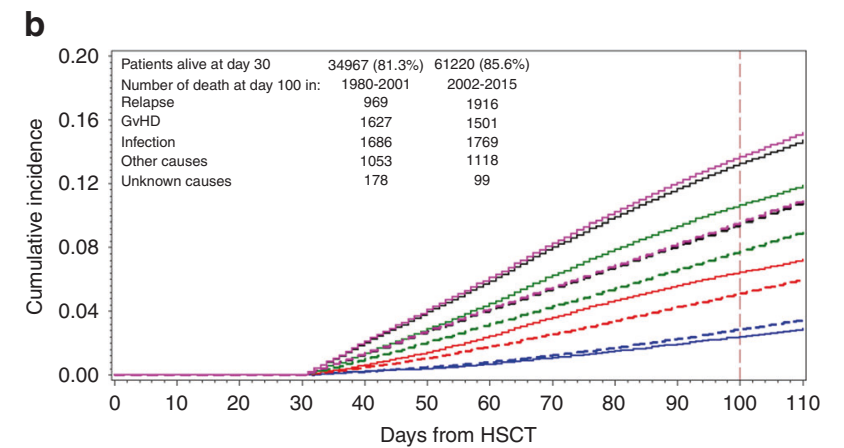

\section{d}

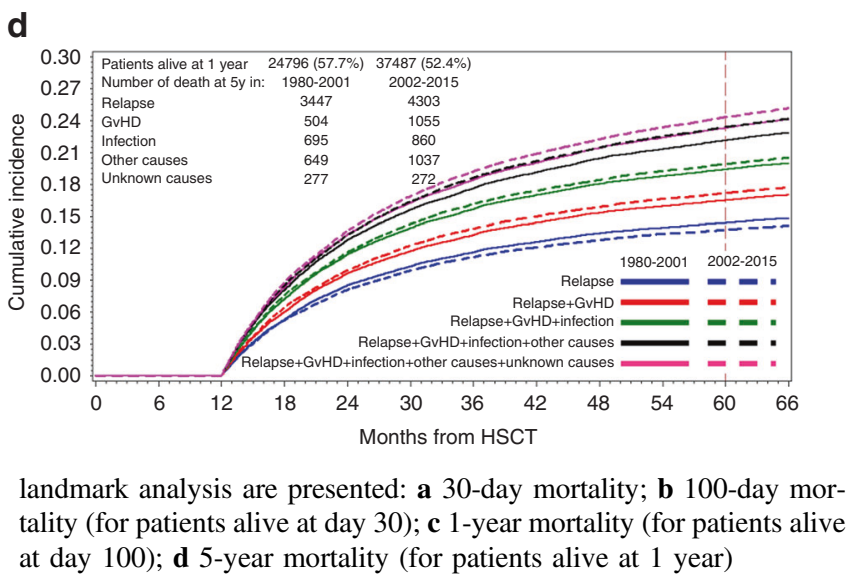

landmark analysis are presented: a 30-day mortality; b 100-day mortality (for patients alive at day 30); c 1-year mortality (for patients alive at day 100); d 5-year mortality (for patients alive at 1 year) a

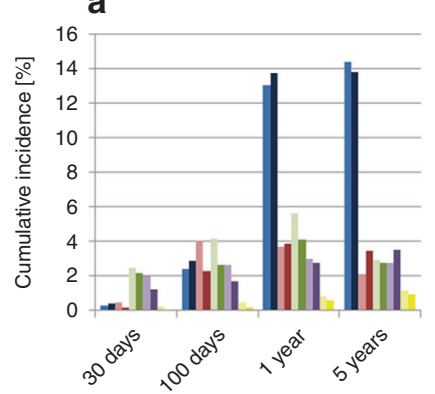

b

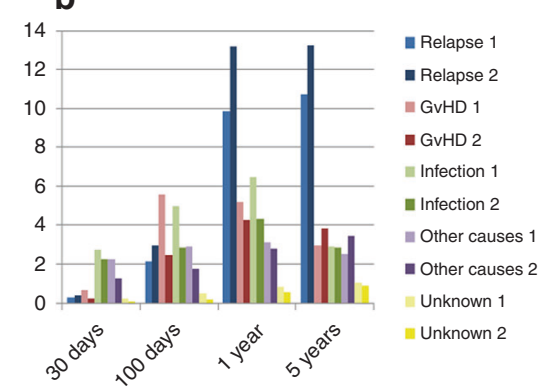

c

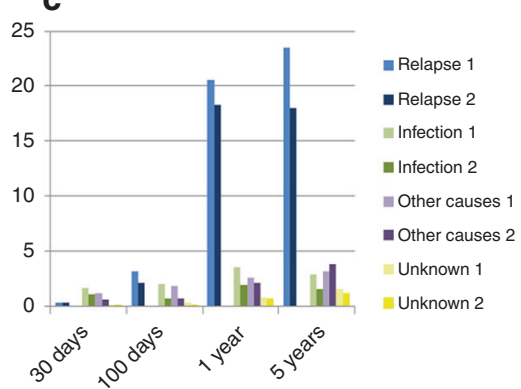

Fig. 2 Main causes of death and of infectious deaths after HSCT. Main cause of death (in \%)by post-transplant phase and by cohorts 1 and 2 $(1=$ cohort $1980-2001 ; 2=$ cohort 2002-2015): a all patients; $\mathbf{b}$ alloHSCT patients; c auto-HSCT patients. Cumulative incidences of

viral, $1 \%$ of parasitic, and $5.2 \%$ of mixed origin (Fig. 3, Fig. S1B). Mortality from mixed/unknown infections increased from cohort 1 to cohort 2 in the very early phase (+30d: 1.35 ; 95\%CI $1.25-1.47$ vs 1.54 ; 95\%CI $1.45-1.63$ ). Mortality from bacterial, viral, fungal and parasitic infections decreased in very early, early, and intermediate phases (Fig. 3, Fig. S1B). In the late phase, mortality from bacterial and fungal infections decreased, while mortality from viral, mixed or unknown infectious etiology did not change (Table S1A). The pattern of infectious deaths, including bacterial, viral, fungal and parasitic infections was similar for allo- and auto-HSCT, but with a distinct and constantly mortality for the respective cause of death during the 4 post-transplant time periods, day 0 to day 30 , day 30 to day 100, day 100 to 1 year, and 1 year to 5 years (see methods section for details), are shown

lower CumInc for all types of infections at all phases after HSCT for auto-HSCT (Tables S1BC, Tables S2-S6).

\section{Factors associated with death from infections}

Factors associated with death from infection after HSCT related to patient, disease, donor-type, stem cell source, year of transplant and center specific macro- or micro-economic properties. Their impact varied significantly depending on main donor type (autologous vs. allogeneic) and the phase after transplant (Table 3A and Table 3B, Fig. S2AB). Increasing age of the patient, advanced disease stage, donor 

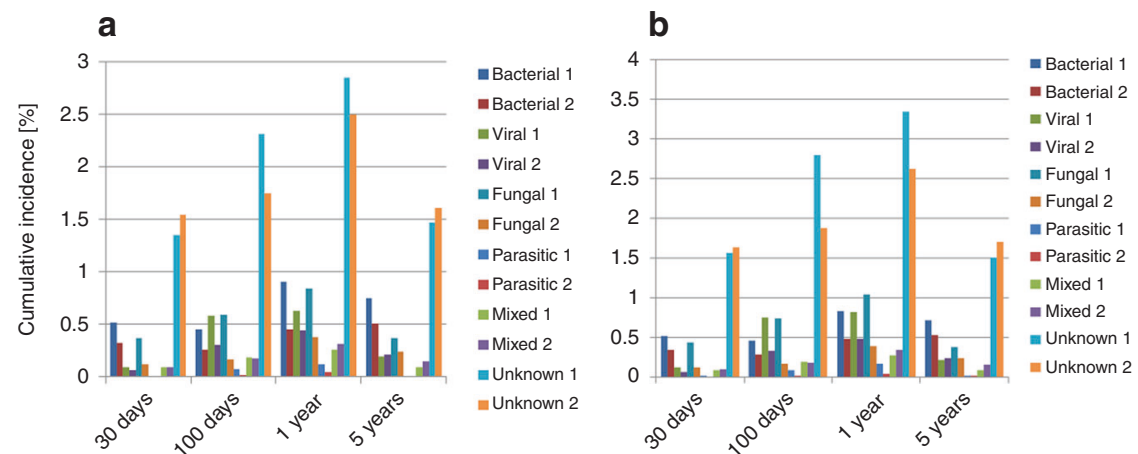

Fig. 3 Main causes of death and of infectious deaths after HSCT. Causes of infectious deaths by post-transplant phase. Changes over time of causes of infectious deaths (in \%) after HSCT for leukemia by post-transplant phase $(1=$ cohort $1980-2001 ; 2=$ cohort 2002-2015): a all patients; b allo-HSCT patients; $\mathbf{c}$ auto-HSCT patients.

type, and second or later transplant were associated with increased risk of infectious death in all phases and for all donor types. Patient sex showed no associations at all.

Peripheral blood as stem cell source was associated with less infectious deaths in all post-transplant phases after autologous HSCT; it was associated with more infectious deaths after allogeneic HSCT in the late phase, reflecting the higher probability of chronic GvHD with peripheral blood. This same association with GvHD in the late phase is reflected by the higher rate of deaths from infections in the $\mathrm{HY}^{+}$donor recipient combinations (Table $3 \mathrm{~A}$ and Table 3B, Fig. S2AB).

Of note, country specific macro-economic factors, GNI/ capita and geographic region, were associated only during the very early and early post-transplant phase; the same applied to centre specific micro-economic factors. Centres with more than 20 years of disease specific transplant experience had significantly less infectious death in the early and intermediate post-transplant phases. No significant association could be documented between death from infections and JACIE accreditation status, in contrast to the association with overall mortality.

\section{Discussion}

The results of this comprehensive study are clear: the European transplant teams have successfully managed to reduce all-cause mortality after autologous HSCT at all post-transplant time phases. In allogeneic HSCT, they were successful in reducing deaths from GVHD, infections and other causes in the very early and early post-transplant time phases, despite an increase in the patient pre-transplant risk profile. In contrast, data did not show a reduction of death from relapse after allogeneic HSCT, and no reduced mortality in the late post-transplant phase. The latter observation is of concern, but indicates areas for improvements.
Cumulative incidences of mortality for the respective cause of death during the 4 post-transplant time periods, day 0 to day 30 , day 30 to day 100 , day 100 to 1 year, and 1 year to 5 years (see methods section for details), are shown

The analysis confirmed well established disease, patient, donor, transplant and center-related risk factors for death from all causes and from infection after transplant $[1,2,21]$. Novel is the observation that not all factors are equally relevant during all post-transplant time phases. Advanced disease stage at time of transplant remains associated with increased risk of mortality from all causes throughout the whole post-transplant phase, and so is increasing age of the recipient, with the exception of the very early phase where other factors dominate. During all post-transplant phases, allogenicity dominates. Of note, the $\mathrm{HY}^{+}$effect adds bearing on mortality primarily after day 100 ; the early beneficial effect of peripheral blood stem cells reverts to a detrimental effect beyond 1 year. As observed earlier, accreditation status of the center is associated with mortality of the patients and with overall improvement over calendar year time [22].

The same risk factors were associated with death from infections. Late disease stage was in all post-transplant phases associated with more infectious deaths. Increasing age contributed to risk of death from infection in a hierarchical effect by decade. Of interest, despite an increase in age in cohort 2, deaths from infections were still reduced, reflecting the possible benefit of better management of infectious complications, through novel diagnostic methods, drugs and guidelines [9-11, 23-25]. Cord blood as a stem cell source was associated with a higher rate of infectious deaths in the first three post-transplant phases, but no longer after 1 year. Peripheral blood as a stem cell source was associated with a lower rate of deaths in the first three phases, not in the last. These results might have been influenced by an additional, indirect late GVHD effect of peripheral blood stem cells. This is supported by the increased risk of infectious deaths in $\mathrm{HY}^{+}$donor recipient combinations. Of note, disease specific center experience in years was strongly associated with reduced infectious deaths in the early post-transplant phase [22]. 
Table 3A Factors associated with death from infection after HSCT in multivariate analysis. Factors associated with death from infection after HSCT in all patients

\begin{tabular}{|c|c|c|c|c|c|c|c|c|c|c|c|c|c|c|c|c|c|c|c|c|c|}
\hline \multirow{3}{*}{ Parameter } & \multirow{3}{*}{ Variables } & \multicolumn{5}{|c|}{30 days } & \multicolumn{5}{|c|}{100 days } & \multicolumn{5}{|c|}{1 year } & \multicolumn{5}{|c|}{5 years } \\
\hline & & \multicolumn{5}{|c|}{ All patients } & \multicolumn{5}{|c|}{ Patients alive at day +30} & \multicolumn{5}{|c|}{ Patients alive at day +100} & \multicolumn{5}{|c|}{ Patients alive at year +1} \\
\hline & & HR & $95 \%$ & HR CI & p & $\mathbf{p}^{*}$ & HR & & IR CI & p & $\mathbf{p}^{*}$ & HR & $95 \%$ & IR CI & p & $\mathbf{p}^{*}$ & HR & $95 \% 1$ & IR CI & p & $\mathbf{p}^{*}$ \\
\hline \multirow{2}{*}{ Year of $\mathrm{HSCT}$} & \begin{tabular}{|l|}
$\mid 1980-2001$ \\
\end{tabular} & 1.503 & 1.349 & 1.676 & $<0.0001$ & \multirow{2}{*}{$<0.0001$} & 1.935 & 1.764 & 2.122 & & \multirow{2}{*}{$<0.0001$} & 1.711 & 1.572 & 1.862 & $<0.0001$ & \multirow{2}{*}{$<0.0001$} & 1.380 & 1.229 & 1.550 & $<0.0001$ & \multirow{2}{*}{$<0.000$} \\
\hline & |2002-2015 & 1.000 & & & & & 1.000 & & & & & 1.000 & & & & & 1.000 & & & & \\
\hline \multirow{2}{*}{ Patient age } & \begin{tabular}{|l} 
Pediatric \\
\end{tabular} & 1.000 & & & & \multirow{2}{*}{$<0.0001$} & 1.000 & & & & \multirow{2}{*}{$<0.0001$} & 1.000 & & & & \multirow{2}{*}{$<0.0001$} & 1.000 & & & & \multirow{2}{*}{$<0.0001$} \\
\hline & Adult & 2.371 & 2.081 & 2.701 & $<0.0001$ & & 1.529 & 1.384 & 1.690 & & & 1.925 & 1.743 & 2.127 & $<0.0001$ & & 2.171 & 1.840 & 2.560 & $<0.0001$ & \\
\hline & Male & & & & & & 1.000 & & & & & & & & & & & & & & \\
\hline the & Female & & & & & 急 & 1.089 & 1.011 & 1.172 & & 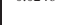 & & & & & so & & & & & \\
\hline & ALL & 1.914 & 1.671 & 2.192 & $<0.0001$ & & 1.126 & 1.015 & 1.250 & 0.0257 & & 1.262 & 1.144 & 1.392 & $<.0001$ & & 1.593 & 1.353 & 1.875 & $<.0001$ & \\
\hline Underlying disease & AML & 1.550 & 1.367 & 1.757 & $<0.0001$ & $<0.0001$ & 0.965 & 0.879 & 1.059 & 0.4525 & 0.0012 & 1.157 & 1.061 & 1.261 & 0.0010 & $<0.0001$ & 1.342 & 1.163 & 1.549 & $<.0001$ & $<0.0001$ \\
\hline & CML & 1.000 & & & & & 1.000 & & & & & 1.000 & & & & & 1.000 & & & & \\
\hline Staee chas & early & 1.000 & & & & $<00001$ & 1.000 & & & & $\leq 00001$ & 1.000 & & & & $\leq 00000$ & 1.000 & & & & $\leq 00001$ \\
\hline Stage class & late & 2.159 & 1.983 & 2.350 & $<0.0001$ & $<0.0001$ & 1.441 & 1.342 & 1.547 & & -0.0001 & 1.424 & 1.334 & 1.520 & $<0.0001$ & -0.0001 & 1.408 & 1.262 & 1.571 & $<0.0001$ & 20.0001 \\
\hline & BM & 1.000 & & & & & 1.000 & & & & & 1.000 & & & & & & & & & \\
\hline Stem cell source & CB & 1.974 & 1.572 & 2.480 & $<0.0001$ & $<0.0001$ & 1.743 & 1.450 & 2.096 & $<.0001$ & $<0.0001$ & 1.355 & 1.107 & 1.658 & 0.0032 & $<0.0001$ & & & & & ns \\
\hline & PB & 0.930 & 0.846 & 1.022 & 0.1303 & & 0.787 & 0.726 & 0.854 & $<.0001$ & & 0.865 & 0.804 & 0.931 & 0.0001 & & & & & & \\
\hline & Autologous & 1.000 & & & & & 1.000 & & & & & 1.000 & & & & & 1.000 & & & & \\
\hline & \begin{tabular}{|l} 
HLA-idsibHY +/matched family $\mathrm{HY}+$ \\
\end{tabular} & 1.541 & 1.295 & 1.835 & $<0.0001$ & & 1.856 & 1.567 & 2.199 & \begin{tabular}{c|c|}
$<.001$ \\
\end{tabular} & & 2.020 & 1.777 & 2.297 & $<.0001$ & & 1.244 & 1.026 & 1.508 & 0.0265 & \\
\hline & HLA-idsibHY-/matched family HY- & 1.390 & 1.203 & 1.607 & $<0.0001$ & & 1.949 & 1.699 & 2.236 & $<.0001$ & & 1.409 & 1.259 & 1.577 & $<0001$ & & 0.939 & 0.801 & 1.102 & 0.4414 & \\
\hline & matched unrelated $\mathrm{HY}^{+}$ & 2.202 & 1.787 & 2.713 & $<0.0001$ & & 3.588 & 2.960 & 4.349 & $<.0001$ & & 3.060 & 2.607 & 3.592 & $<.0001$ & & 1.718 & 1.332 & 2.217 & $<.0001$ & \\
\hline Type of HSCT & matched unrelated HY- & 1.970 & 1.688 & 2.298 & $<0.0001$ & $<0.0001$ & 3.505 & 3.037 & 4.044 & $<.0001$ & $<0.0001$ & 2.447 & 2.171 & 2.758 & $<0001$ & $<0.0001$ & 1.445 & 1.217 & 1.716 & $<.0001$ & $<0.0001$ \\
\hline & mismatched family & 3.452 & 2.906 & 4.100 & $<0.0001$ & & 6.167 & 5.253 & 7.241 & $<0.0001$ & & 4.514 & 3.909 & 5.213 & $<.0001$ & & 2.138 & 1.663 & 2.748 & $<.0001$ & \\
\hline & \begin{tabular}{|l} 
mismatched unrelated \\
\end{tabular} & 1.884 & 1.491 & 2.381 & $<0.0001$ & & 4.147 & 3.428 & 5.017 & $<0.0001$ & & 3.380 & 2.851 & 4.008 & $<.0001$ & & 1.480 & 1.103 & 1.985 & 0.0089 & \\
\hline & syngeneic & 1.156 & 0.595 & 2.249 & 0.6684 & & 1.242 & 0.660 & 2.335 & 0.5015 & & 0.713 & 0.369 & 1.381 & 0.3161 & & 1.122 & 0.577 & 2.184 & 0.7339 & \\
\hline V & First & 1.000 & & & & & 1.000 & & & & 5000 & 1.000 & & & & 0 & 1.000 & & & & 00004 \\
\hline Number of HSC 1 & Second or more & 2.274 & 2.056 & 2.515 & $<0.0001$ & $<0.0001$ & 1.864 & 1.688 & 2.059 & $<0.0001$ & $<0.0001$ & 1.158 & 1.036 & 1.294 & 0.0100 & 0.0100 & 1.392 & 1.161 & 1.669 & 0.0004 & 0.0004 \\
\hline & north-west & 1.000 & & & & & & & & & & & & & & & & & & & \\
\hline Geographic region & east & 1.442 & 1.248 & 1.667 & $<0.0001$ & $<0.0001$ & & & & & ns & & & & & ns & & & & & ns \\
\hline & south & 1.153 & 1.052 & 1.265 & 0.0024 & & & & & & & & & & & & & & & & \\
\hline 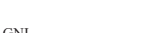 & high income & 1.000 & & & & 000 & 1.000 & & & & 0018.9 & & & & & a & & & & & \\
\hline & upper/lower middle income & 1.310 & 1.130 & 1.519 & 0.0003 & & 1.185 & 1.029 & 1.364 & 0.0185 & & & & & & & & & & & \\
\hline & Accredited/Expired & & & & & 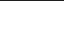 & & & & & 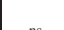 & 1.000 & & & & 00275 & & & & & \\
\hline JACIE actrentation 2010 & Withdrawn/not accredited & & & & & nis & & & & & nis & 0.923 & \begin{tabular}{|l|l}
0.860 \\
\end{tabular} & 0.991 & 0.0275 & 0.0273 & & & & & nis \\
\hline & $0-4$ & 1.564 & 1.327 & 1.844 & $<0.0001$ & & 1.361 & 1.178 & 1.573 & $<.0001$ & & 1.294 & 1.136 & 1.474 & 0.0001 & & & & & & \\
\hline Centre experience & 5-19 & 1.351 & 1.226 & 1.489 & $<0.0001$ & $<0.0001$ & 1.316 & 1.212 & 1.428 & $<.0001$ & $<0.0001$ & 1.138 & 1.057 & 1.225 & 0.0006 & $<0.0001$ & & & & & ns \\
\hline & $20+$ & 1.000 & & & & & 1.000 & & & & & 1.000 & & & & & & & & & \\
\hline
\end{tabular}

Centre size was defined for each transplant by the number of transplants performed in the center for the main disease of the patient in the year of the transplant $(0-4,5-19,20+$ transplants). Centre experience in years was defined by the number of years that the center had performed transplants until the year of the transplant of the patient $(0-4,5-19,20+$ years of program). Country macroeconomic status was defined by gross national income (GNI/capita) in 2016 (high income, upper middle income, lower middle income) (source: www.worldbank.org). Geographical regions were defined as: north-western (Austria, Belgium, Denmark, Finland, France, Germany, Luxembourg, Netherlands, Norway, Sweden, Switzerland, UK), eastern (Bulgaria, Croatia, Czech Republic, Hungary, Lithuania, Macedonia, Poland, Romania, Russia, Slovakia) and southern (Cyprus, Greece, Israel, Italy, Portugal, Spain, Turkey, and other EBMT countries). JACIE accreditation status (accredited, expired, withdrawn and not accredited) in 2016 was used. HR > 2.0 is highlighted in orange; HR $>1.5$ is highlighted in yellow.

There are major caveats in this study. It looks at very heterogeneous data over a long time period with many changes in disease indications, choice of donor type, stem cell source. over calendar year time. Data were derived from a multitude of centers from many countries with different micro- and macroeconomic backgrounds. Some data, such as cytogenetic profiles were not in the data set. Some decisions had to be arbitrary, such as the use of economic factors as of the year 2016. Centers had varying attitudes regarding data collection, and potentially different interpretations of "cause of death". Simply, we used the data as they were reported to the database, and we accepted the information as given by the center, including the high rate of deaths and infectious deaths of "unknown" origin. Still, the consistency of the findings in the four post-transplant phases, and the confirmation of key risk factor elements are strong arguments that the data are valid. They were as well in line with our pre-set hypotheses, that factors associated with overall mortality and from infections would differ depending on the post-transplant phase. This was the case, but is of concern. Mortality was reduced early post-transplant, but increased in the late phase after allogeneic HSCT. Hence, improvements were more rapidly visible than deteriorations; the increase in late mortality years after the transplant might not be recognized to the same extent, with patients frequently at distance from the center. Lethal 
Table 3B Factors associated with death from infection after allogeneic HSCT only in the second cohort

\begin{tabular}{|c|c|c|c|c|c|c|c|c|c|c|c|c|c|c|c|c|c|c|c|c|c|}
\hline \multirow{5}{*}{$\begin{array}{l}\text { Parameter } \\
\text { Patient age }\end{array}$} & \multirow{4}{*}{\begin{tabular}{|l|} 
Variables \\
Pediatric \\
\end{tabular}} & \multicolumn{5}{|c|}{30 days } & \multicolumn{5}{|c|}{100 days } & \multicolumn{5}{|c|}{1 year } & \multicolumn{5}{|c|}{5 years } \\
\hline & & \multicolumn{5}{|c|}{ All patients } & \multicolumn{5}{|c|}{ Patients alive at day +30} & \multicolumn{5}{|c|}{ Patients alive at day +100} & \multicolumn{5}{|c|}{ Patients alive at year +1} \\
\hline & & \multirow{2}{*}{\begin{tabular}{|c|} 
HR \\
1.000 \\
\end{tabular}} & \multicolumn{2}{|c|}{$95 \%$ HR CI } & \multirow[t]{2}{*}{$\mathrm{p}$} & \multirow{3}{*}{\begin{tabular}{|c|}
$\mathbf{p}^{*}$ \\
$<0.0001$
\end{tabular}} & HR & \multicolumn{2}{|c|}{$95 \%$ HR CI } & \multirow[t]{2}{*}{$\mathrm{p}$} & \multirow{3}{*}{$\begin{array}{c}\mathbf{p}^{*} \\
\mathrm{~ns}\end{array}$} & \multirow{3}{*}{$\begin{array}{l}\text { HR } \\
1.000 \\
1.779\end{array}$} & \multicolumn{2}{|c|}{$95 \% \mathrm{HRCI}$} & \multirow{3}{*}{$\begin{array}{c}\mathbf{p} \\
<0.0001 \\
\end{array}$} & \multirow{3}{*}{\begin{tabular}{|c}
$\mathbf{p}^{*}$ \\
$<0.0001$
\end{tabular}} & \multirow{3}{*}{\begin{tabular}{|c|} 
HR \\
1.000 \\
2.432 \\
\end{tabular}} & $95 \%$ & R CI & $\mathbf{p}$ & $\mathrm{p}^{*}$ \\
\hline & & & & & & & & & & & & & & & & & & & & & \\
\hline & Adult & 2.741 & 2.267 & 3.313 & $<0.0001$ & & & & & & & & 1.541 & 2.053 & & & & 1.865 & 3.171 & $<0.0001$ & $<0.0001$ \\
\hline & ALL & 2.621 & 2.036 & 3.374 & $<0.0001$ & & 1.362 & 1.126 & 1.648 & 0.0015 & & & & & & & & & & & \\
\hline Underlying disease & AML & 1.945 & 1.525 & 2.480 & $<0.0001$ & $<0.0001$ & 1.144 & 0.953 & 1.373 & 0.1478 & 0.0005 & & & & & ns & & & & & ns \\
\hline & CML & 1.000 & & & & & 1.000 & & & & & & & & & & & & & & \\
\hline & early & 1.000 & & & & & 1.000 & & & & & 1.000 & & & & & 1.000 & & & & \\
\hline Stage class & late & 2.250 & 2.006 & 2.524 & $<0.0001$ & $<0.0001$ & 1.456 & 1.318 & 1.609 & $<0.0001$ & $<0.0001$ & 1.322 & 1.208 & 1.447 & $<0.0001$ & $<0.0001$ & 1.298 & 1.119 & 1.505 & 0.0006 & 0.0006 \\
\hline & BM & 1.000 & & & & & 1.000 & & & & & 1.000 & & & & & 1.000 & & & & \\
\hline Stem cell source & $\mathrm{CB}$ & 2.391 & 1.834 & 3.117 & $<0.0001$ & $<0.0001$ & 1.738 & 1.397 & 2.162 & $<0.0001$ & $<0.0001$ & 1.718 & 1.362 & 2.167 & $<0.0001$ & $<0.0001$ & 1.901 & 1.242 & 2.911 & 0.0031 & 0.0011 \\
\hline & PB & 1.041 & 0.904 & 1.197 & 0.5788 & & 1.004 & 0.892 & 1.130 & 0.9506 & & 1.131 & 1.010 & 1.266 & 0.0323 & & 1.328 & 1.104 & 1.599 & 0.0027 & \\
\hline & HLA-idsibHY-/matched family HY- & 1.000 & & & & & 1.000 & & & & & 1.000 & & & & & 1.000 & & & & \\
\hline & $\begin{array}{l}\text { HLA-idsibHY }+ \text { /matched family } \mathrm{HY}+ \\
\end{array}$ & 0.981 & 0.790 & $\begin{array}{ll}1.217 \\
\end{array}$ & \begin{tabular}{|l|}
0.8601 \\
\end{tabular} & & 0.991 & 0.795 & 1.235 & 0.9328 & & 1.354 & 1.139 & 1.609 & \begin{tabular}{|l|}
0.0006 \\
\end{tabular} & & 1.545 & 1.212 & 1.968 & 0.0004 & \\
\hline & matched unrelated $\mathrm{HY}^{+}$ & 1.475 & 1.181 & 1.843 & 0.0006 & & 2.110 & 1.722 & 2.585 & $<0.0001$ & & 2.304 & 1.932 & 2.749 & $<0.0001$ & & 1.691 & 1.260 & 2.268 & 0.0005 & \\
\hline Type of HSCT & matched unrelated HY- & 1.322 & 1.146 & 1.526 & 0.0001 & $<0.0001$ & 2.022 & 1.764 & 2.317 & $<0.0001$ & $<0.0001$ & 1.893 & 1.683 & 2.130 & $<0.0001$ & $<0.0001$ & 1.510 & 1.264 & 1.804 & $<0.0001$ & $<0.0001$ \\
\hline & mismatched family & 2.564 & 2.151 & 3.056 & $\begin{array}{l}<0.0001 \\
\end{array}$ & & 3.451 & 2.902 & 4.104 & $<0.0001$ & & 3.762 & 3.205 & 4.414 & $<0.0001$ & & 2.783 & 2.087 & 3.712 & $<0.0001$ & \\
\hline & mismatched unrelated & 1.197 & 0.903 & 1.586 & 0.2109 & & 2.609 & 2.090 & 3.256 & $<0.0001$ & & 2.497 & 2.039 & 3.059 & $<0.0001$ & & 1.624 & 1.153 & 2.287 & 0.0055 & \\
\hline & syngeneic & 2.210 & 1.095 & 4.458 & 0.0268 & & 0.303 & 0.043 & 2.160 & 0.2336 & & 0.222 & 0.031 & 1.574 & 0.1320 & & - & & & & \\
\hline N & First & 1.000 & & & & 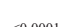 & 1.000 & & & & 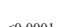 & 1.000 & & & & & 1.000 & & & & $00037+2$ \\
\hline Number of HSCT & Second or more & 2.155 & 1.892 & 2.454 & $<0.0001$ & $<0.0001$ & 1.815 & 1.590 & 2.072 & $<0.0001$ & $<0.0001$ & 1.261 & 1.098 & 1.448 & 0.001 & 0.001 & 1.407 & 1.118 & 1.772 & 0.0037 & 0.0037 \\
\hline & north-west & 1.000 & & & & & & & & & & & & & & & & & & & \\
\hline Geographic region & east & 1.454 & 1.210 & 1.747 & $<0.0001$ & $<0.0001$ & & & & & ns & & & & & ns & & & & & ns \\
\hline & south & 1.216 & 1.070 & 1.382 & 0.0027 & & & & & & & & & & & & & & & & \\
\hline GNI & high income & 1.000 & & & & 0.0047 & 1.000 & & & & $<00001$ & & & & & ns & & & & & ns \\
\hline & upper/lower middle income & 1.287 & 1.080 & 1.533 & 0.0047 & & 1.399 & 1.188 & 1.647 & $<0.0001$ & & & & & & & & & & & \\
\hline & $0-4$ & 1.266 & 0.924 & 1.734 & 0.1424 & & 0.983 & 0.713 & 1.356 & 0.9175 & & 1.074 & 0.810 & 1.423 & \begin{tabular}{|l|}
0.6213 \\
\end{tabular} & & & & & & \\
\hline Centre experience & $5-19$ & 1.381 & 1.231 & 1.549 & $<0.0001$ & $<0.0001$ & 1.261 & 1.138 & 1.397 & $<0.0001$ & $<0.0001$ & 1.184 & 1.083 & 1.295 & 0.0002 & 0.001 & & & & & ns \\
\hline & $20+$ & 1.000 & & & & & 1.000 & & & & & 1.000 & & & & & & & & & \\
\hline
\end{tabular}

infections caused by bacteria and fungi were reduced at any time point, but not infections of unknown origin.

This high rate of "unknown " infections is intriguing and of prime concern. The constant pattern in all reporting centers, over calendar year time and over all post-transplant phases indicates that it might be a real entity, but without the same awareness as any specified infection. There is no information in the data set, whether the appropriate tests were not done, were not successful, or whether organ-related infections, such as pneumonia with negative microbiological work up were simply classified as such [15]. It will be essential for the future to learn whether "unknown" includes hitherto unknown infectious agents, or might be a set of multiple immune response syndromes. The focus on specified risk groups will support such strategies. Late infectious mortality as an entity remains of concern. It presents a complicated issue, probably resulting from the negative effects of many variables such as GVHD, inadequate immune recovery, poor graft function, increasing co-morbidities with increasing age. It might reflect as well the variable expertise of health care providers in the different transplant centers for the long-term follow-up of their patients.

What are the consequences of this report? The positive message is that outcomes were and can be improved. With similar efforts in late post-transplant care, it will be possible to improve outcome beyond 1 year as well. The first step is to become aware of the reality, to shift efforts, and to focus on preventable and reversible late complications. Strategies will need to include efforts for better identification of causes and treatment of mixed and "unknown" infections through collaborative efforts. Older patients, those with a second or later transplant and those with mismatched allogeneic transplants remain at higher risk, even years after transplant. They might require targeted follow-up programs. Prospective studies assessing causes of death 5 years or more after HSCT could help to characterize and possibly to target efforts to prevent late mortality. Finally, the major role of "allogeneicity" in death after allogeneic compared to autologous HSCT might lead to reconsider more carefully risk adapted indications for allogeneic HSCT.

Public health bodies and transplant teams need to recognize that fatal events can occur many months or years after the transplant procedure. Early detection and rapid treatment, particularly of infections, requires allocation of resources. Support includes data collection and data analysis which are integral parts of any transplant therapy [26]. Recent FACT-JACIE standards have incorporated longterm follow-up strategies between specialist transplant centers and local health-care services. Given the long time horizons, this will require support in planning and resources 
by public health bodies [27-29]. Furthermore, in the era of precision medicine and targeted therapies, HSCT has to provide best outcome regarding overall survival, quality of life and costs compared to any other treatment strategy [16]. Careful and continuing analysis of large data sets will help to achieve this goal.

Acknowledgements The authors acknowledge the cooperation of the participating teams and their staff. They acknowledge the excellent work of the EBMT and IDWP Data Office in Leiden.

Funding The study was funded by the European Group for Blood and Marrow Transplantation EBMT. EBMT is supported by grants from the corporate members: Amgen Europe, ViroPharma Europe, Celgene International SARL, Genzyme Europe B.V., Gilead Sciences Europe Ltd., MiltenyiBiotec GmbH, Schering-Plough International Inc., Bristol Myers Squibb, Caridia BCT Europe NV, Cephalon Europe, F. Hoffmann-La Roche Ltd, Fresenius Biotech GmbH, Therakos Inc., Alexion Europe, Chugai Sanofi-Aventis, Merck Sharp and Dohme, Novartis, Pfizer, Pierre Fabre Médicament.

Author contributions JS, GT and AG designed the study concept, and drafted the manuscript. $\mathrm{LK}, \mathrm{AvB}, \mathrm{SvW}$, and $\mathrm{HB}$ were responsible for the data collection and assembly. GT and SI conducted the statistical analysis. MM, LG, CC, PL, DA, SC, RC, PB, GB, CB, RD, CD, JK, $\mathrm{AL}, \mathrm{SM}, \mathrm{AN}, \mathrm{JAS}, \mathrm{NK}$ and $\mathrm{MM}$ were responsible for the integrity of the data and gave scientific input. All authors have seen the final version and approved of it. Writing of the manuscript was the sole responsibility of the authors. There are no conflicts of interest to declare.

\section{Compliance with ethical standards}

Conflict of interest The authors declare that they have no conflict of interest.

Publisher's note: Springer Nature remains neutral with regard to jurisdictional claims in published maps and institutional affiliations.

Open Access This article is licensed under a Creative Commons Attribution 4.0 International License, which permits use, sharing, adaptation, distribution and reproduction in any medium or format, as long as you give appropriate credit to the original author(s) and the source, provide a link to the Creative Commons license, and indicate if changes were made. The images or other third party material in this article are included in the article's Creative Commons license, unless indicated otherwise in a credit line to the material. If material is not included in the article's Creative Commons license and your intended use is not permitted by statutory regulation or exceeds the permitted use, you will need to obtain permission directly from the copyright holder. To view a copy of this license, visit http://creativecommons. org/licenses/by/4.0/.

\section{References}

1. Gratwohl A, Brand R, Frassoni F, Rocha V, Niederwieser D, Reusser $\mathrm{P}$, et al. Cause of death after allogeneic haematopoietic stem cell transplantation (HSCT) in early leukaemias: an EBMT analysis of lethal infectious complications and changes over calendar time. Bone Marrow Transpl. 2005;36:757-69.

2. Gooley TA, Chien JW, Pergam SA, Hingorani S, Sorror ML, Boeckh M, et al. Reduced mortality after allogeneic hematopoieticcell transplantation. N Engl J Med. 2010;363:2091-101.
3. Gratwohl A, Pasquini MC, Aljurf M, Atsuta Y, Baldomero H, Foeken L, et al. One million haemopoietic stem-cell transplants: a retrospective observational study. Lancet Haematol. 2015;2:e91-100.

4. Passweg JR, Baldomero H, Bader P, Bonini C, Duarte RF, Dufour C, et al. Use of haploidentical stem cell transplantation continues to increase: the 2015 European Society for Blood and Marrow Transplant activity survey report. Bone Marrow Transpl. 2017;52: 811-7.

5. Sureda A, Bader P, Cesaro S, Dreger P, Duarte RF, Dufour C, et al. Indications for allo- and auto-SCT for haematological diseases, solid tumours and immune disorders: current practice in Europe, 2015. Bone Marrow Transpl. 2015;50:1037-56.

6. Gratwohl A, Baldomero H, Passweg J, Urbano-Ispizua A. Increasing use of reduced intensity conditioning transplants: report of the 2001 EBMT activity survey. Bone Marrow Transpl. 2002;30:813-31.

7. Finke J, Schmoor C, Bethge WA, Ottinger HD, Stelljes M, Zander $\mathrm{AR}$, et al. Prognostic factors affecting outcome after allogeneic transplantation for hematological malignancies from unrelated donors: results from a randomized trial. Biol Blood Marrow Transpl. 2012;18:1716-26.

8. Kolb HJ, Mittermuller J, Clemm C, Holler E, Ledderose G, Brehm $\mathrm{G}$, et al. Donor leukocyte transfusions for treatment of recurrent chronic myelogenous leukemia in marrow transplant patients. Blood. 1990;76:2462-5.

9. Averbuch D, Cordonnier C, Livermore DM, Mikulska M, Orasch $\mathrm{C}$, Viscoli $\mathrm{C}$, et al. Targeted therapy against multi-resistant bacteria in leukemic and hematopoietic stem cell transplant recipients: guidelines of the 4th European Conference on Infections in Leukemia (ECIL-4, 2011). Haematologica. 2013;98:1836-47.

10. Averbuch D, Orasch C, Cordonnier C, Livermore DM, Mikulska $\mathrm{M}$, Viscoli C, et al. European guidelines for empirical antibacterial therapy for febrile neutropenic patients in the era of growing resistance: summary of the 2011 4th European Conference on Infections in Leukemia. Haematologica. 2013;98:1826-35.

11. Tissot F, Agrawal S, Pagano L, Petrikkos G, Groll AH, Skiada A, et al. ECIL-6 guidelines for the treatment of invasive candidiasis, aspergillosis and mucormycosis in leukemia and hematopoietic stem cell transplant patients. Haematologica. 2017;102:433-44.

12. Winston DJ, Young JA, Pullarkat V, Papanicolaou GA, Vij R, Vance E, et al. Maribavir prophylaxis for prevention of cytomegalovirus infection in allogeneic stem cell transplant recipients: a multicenter, randomized, double-blind, placebo-controlled, doseranging study. Blood. 2008;111:5403-10.

13. Marty FM, Winston DJ, Rowley SD, Vance E, Papanicolaou GA, Mullane KM, et al. CMX001 to prevent cytomegalovirus disease in hematopoietic-cell transplantation. N Engl J Med. 2013;369: 1227-36.

14. Marty FM, Ljungman P, Chemaly RF, Maertens J, Dadwal SS, Duarte RF, et al. Letermovir prophylaxis for cytomegalovirus in hematopoietic-cell transplantation. N Engl J Med. 2017;377:2433-44.

15. Hahn T, Sucheston-Campbell LE, Preus L, Zhu X, Hansen JA, Martin PJ, et al. Establishment of definitions and review process for consistent adjudication of cause-specific mortality after allogeneic unrelated-donor hematopoietic cell transplantation. Biol Blood Marrow Transpl. 2015;21:1679-86.

16. Gratwohl A, Sureda A, Cornelissen J, Apperley J, Dreger P, Duarte R, et al. Alloreactivity: the Janus-face of hematopoietic stem cell transplantation. Leukemia. 2017;31:1752-9.

17. Glucksberg H, Storb R, Fefer A, Buckner CD, Neiman PE, Clift $\mathrm{RA}$, et al. Clinical manifestations of graft-versus-host disease in human recipients of marrow from HL-A-matched sibling donors. Transplantation. 1974;18:295-304.

18. Gratwohl A, Sureda A, Baldomero H, Gratwohl M, Dreger P, Kröger $\mathrm{N}$, et al. Economics and outcome after hematopoietic stemcell transplantation: a retrospective cohort study. EBioMedicine. 2015;2:2101-9. 
19. Iacobelli S. Suggestions on the use of statistical methodologies in studies of the European Group for Blood and Marrow Transplantation. Bone Marrow Transpl. 2013;48(Suppl 1):S1-37.

20. Klein JP, Moeschberger ML. Survival analysis: techniques for censored and truncated data. New York: Springer-Verlag; 2003.

21. Meyers JD, Bowden RA, Counts GW. Infectious complications of marrow transplant: risk factors for infection. Prog Clin Biol Res. 1989;309:357-66.

22. Gratwohl A, Brand R, McGrath E, van Biezen A, Sureda A, Ljungman $\mathrm{P}$, et al. Use of the quality management system "JACIE" and outcome after hematopoietic stem cell transplantation. Haematologica. 2014;99:908-15.

23. Ljungman P, de la Camara R, Cordonnier C, Einsele H, Engelhard D, Reusser P, et al. Management of CMV, HHV-6, HHV-7 and Kaposi-sarcoma herpesvirus (HHV-8) infections in patients with hematological malignancies and after SCT. Bone Marrow Transpl. 2008;42:227-40.

24. Styczynski J, van der Velden W, Fox CP, Engelhard D, de la Camara R, Cordonnier C, et al. Management of Epstein-Barr Virus infections and post-transplant lymphoproliferative disorders in patients after allogeneic hematopoietic stem cell transplantation:
Sixth European Conference on Infections in Leukemia (ECIL-6) guidelines. Haematologica. 2016;101:803-11.

25. Tichelli A, Rovo A, Gratwohl A Late pulmonary, cardiovascular, and renal complications after hematopoietic stem cell transplantation and recommended screening practices. Hematol Am Soc Hematol Educ Program 2008:125-33.

26. World Health Organization. WHO guiding principles on human cell, tissue and organ transplantation. Transplantation. 2010;90: 229-33.

27. Snowden JA, McGrath E, Duarte RF, Saccardi R, Orchard K, Worel $\mathrm{N}$, et al. JACIE accreditation for blood and marrow transplantation: past, present and future directions of an international model for healthcare quality improvement. Bone Marrow Transpl. 2017;52:1367-71.

28. Hamblin A, Greenfield DM, Gilleece M, Salooja N, Kenyon M, Morris E, et al. Provision of long-term monitoring and late effects services following adult allogeneic haematopoietic stem cell transplant: a survey of UK NHS-based programmes. Bone Marrow Transpl. 2017;52:889-94.

29. Miller PDE, de Silva TI, Skinner R, Gilleece M, Peniket A, Hamblin A, et al. Routine vaccination practice after adult and paediatric allogeneic haematopoietic stem cell transplant: a survey of UK NHS programmes. Bone Marrow Transpl. 2017;52:1082.

\section{Affiliations}

Jan Styczyński ${ }^{1}$ - Gloria Tridello ${ }^{2}$. Linda Koster ${ }^{3}$ - Simona lacobelli ${ }^{4}$ - Anja van Biezen ${ }^{3} \cdot$ Steffie van der Werf ${ }^{3}$.

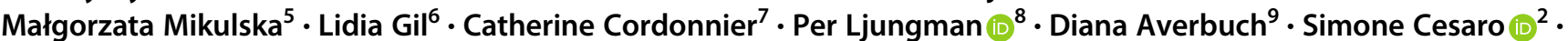

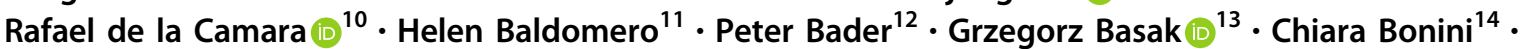
Rafael Duarte ${ }^{15}$. Carlo Dufour ${ }^{16}$. Jurgen Kuball ${ }^{17}$ - Arjan Lankester ${ }^{18}$ - Silvia Montoto ${ }^{19}$ - Arnon Nagler ${ }^{20}$. John A. Snowden ${ }^{21}$ - Nicolaus Kröger ${ }^{22} \cdot$ Mohamad Mohty $^{23} \cdot$ Alois Gratwohl $^{24}$ for the Infectious Diseases Working Party EBMT

1 Pediatric Hematology and Oncology, Collegium Medicum, Nicolaus Copernicus University Torun, Bydgoszcz, Poland

2 Policlinico G.B. Rossi, Verona, Italy

3 EBMT Data Office, Leiden, The Netherlands

4 Università di Roma "Tor Vergata”, Roma, Italy

5 Division of Infectious Diseases, University of Genoa (DISSAL) and Ospedale Policlinico San Martino, Genoa, Italy

6 Medical University, Poznań, Poland

7 Hôpital Henri Mondor, Assistance Publique-Hopitaux de Paris (AP-HP) and Paris-Est-Créteil University, Creteil, France

8 Karolinska University Hospital, and Karolinska Institutet Stockholm, Stockholm, Sweden

9 Hadassah University Hospital, Jerusalem, Israel

10 Hospital de la Princesa, Madrid, Spain

11 EBMT Activity Survey Office, Hematology, Department of Medicine, University Hospital, Basel, Switzerland

12 Universitätsklinikum Frankfurt, Goethe-Universität, Frankfurt am Main, Germany
13 Department of Hematology, Oncology and Internal Medicine, Medical University of Warsaw, Warsaw, Poland

14 Università Vita-Salute San Raffaele, Milan, Italy

15 Hospital Universitario Puerta de Hierro Majadahonda, Madrid, Spain

16 Hematology Unit, G. Gaslini Children's Institute, Genova, Italy

17 Department of Haematology, University Medical Centre, Utrecht, The Netherlands

18 Leiden University Hospital, Leiden, The Netherlands

19 Department of Haemato-oncology, St Bartholomew's Hospital, Barts Health NHS Trust, London, UK

20 Chaim Sheba Medical Center, Tel-Hashomer, Israel

21 Sheffield Teaching Hospitals NHS Foundation Trust, Sheffield, UK

22 Department of Stem Cell Transplantation, University Hospital Eppendorf, Hamburg, Germany

23 Department of Hematology, Hospital Saint Antoine, Paris, France

24 Hematology, Medical Faculty, University of Basel, Basel, Switzerland 